EPiC Series in Built Environment
Volume 1, 2020, Pages 419-427
Associated Schools of Construction Proceed-
ings of the 56th Annual International Conference

\title{
Market Share Metrics and Data Analysis of the U.S. Union Electrical Construction Industry
}

\author{
Hisham Said ${ }^{1}$ and Aishwarya Mali ${ }^{1}$ \\ ${ }^{1}$ Santa Clara University, Santa Clara, California
}

Despite the union's strive for better labor life and work conditions, unionization in the U.S. construction industry has dropped to half of its 2008 levels. Measuring construction unionization, or union market share, is challenging due to the fragmented nature of the construction businesses and the high mobility of the construction workers. This paper provides a comparative assessment of four available market share metrics that have been applied in the unionized electrical construction industry. In addition, a new market share trend metric is proposed to help in developing a better understanding of the construction industry unionization dynamics.

Key Words: Electrical construction, union, labor relations, quantitative metrics

\section{Introduction}

In the U.S., the National Labor Agreement Act of 1975 granted most of the workers the right to join or form a union to bargain and negotiate with their employers acceptable work conditions and pay rates. Labor unions improve the life quality and work conditions of both union and non-union (open shop) workers, in terms of higher wage rates, better benefits, sophisticated training, and safer workplaces (Walter and Mishel 2003). However, the unions in the U.S. experienced a significant decline in membership from 20.1\% in 2008 to 10.5\% in 2018 (USBLS 2019). The construction industry is not different from other private economic sectors, in terms of experiencing this decline in unionization and the market share of trade unions and their signatory contractors.

Few research studies investigated the unionization of the construction industry. Multiple researchers found that unionized workplaces are more productive than their open shop counterparts (Freeman and Medoff 1983, Allen 1984). However, Diekmann and Peppler (1984) found that union contractors incur 45\% more costs than open shop contractors. Maloney and McFillen (1994) found that union workers enjoy more structured job definitions, while nonunion workers enjoy more autonomy. Lim and Philips (2012) analyzed a case study of a unionized industrial construction project to determine the factors that contribute to the dismissal of union workers. No research studies were conducted to 
quantitatively analyze the dynamics of union and open-shop labor marketplace, because the researchers lack the knowledge of available union market share metrics and the access to their data.

Measuring the trade union market share is challenging due to the fragmented decentralized nature of the construction industry that limits the availability of quantitative union market share metrics. Construction unionization and its quantification is limited due to: 1 ) the extreme fragmentation of the industry businesses and processes; 2) higher specialization of its workers; 3 ) the temporary nature of construction projects and labor affiliation to a single employer; and 4) easy entry of documented and undocumented immigrants in the construction industry. Multiple previous research studies investigated the controlling factors of construction trade unionization (Erlich and Grabelsky 2005; Belman and Smith 2008; Kosla 2015), but they mainly depended on a qualitative approach.

This paper provides a comparative assessment of the available metrics that have been used to measure the market share of electrical trade unions, and presents a new metric for classifying the market share trend that can be the basis for future research on union construction dynamics. Electrical construction was selected as a representative of other industry trades, due to the business similarity between the different trades as enforced by the federal regulations. The unionized electrical workers in the U.S. are represented by the International Brotherhood of Electrical Workers (IBEW), while their employers are represented by the National Electrical Contractors Association (NECA). The paper is organized as follows. The methodologies, applications, and limitations of available union market share metrics are described and contrasted. Afterwards, the new market share trend metric is described, and the future possible research initiatives are suggested.

\section{Union Electrical Construction Market Share Metrics}

Four union market share metrics have been utilized by the electrical construction union, and they were contrasted in terms of reporting consistency, reporting frequency, reliability, accuracy, public availability, and detailing of market segments. The information of these metrics was collected mostly from interviews conducted with labor-management relations staff at IBEW and NECA.

\section{CLRC Inside Construction Trends Report}

Construction Labor Research Council (CLRC) is a private industry research entity that has provided market research services to trade organizations for over 30 years. NECA is member of the CLRC governing board that is made up of other similar trade organizations. These organizations pay a membership fee in return of some basic services, including the Inside Construction Trend (ICT) studies that NECA has obtained since 1972.

The ICT study depends on integrating employment and wage data from the National Electrical Benefits Fund (NEBF); that is contrasted with the data from the U.S. Bureau of Census (BOC) and the Bureau of Labor Statistics (BLS). The ICT report calculates three market share metrics for the NECA chapters, districts, and national levels: 1 ) employers share (signatory contractors vs open shop), 2) employees share (number of signatory electricians vs open shops); and 3) wage share. The calculations of these metrics are shown in Figure 1. First, the ICT report depends on the employment and wage data reported to the NEBF by its covered employers, as reflected on their monthly payroll reports, and as published annually by the executive secretary/treasurer of NEBF. Second, NECA membership is obtained to reflect the number of NECA members in good standing at the end of each year. Third, the business attributes (employment, wages, number of firms) are obtained from BOC and BLS for the electrical construction industry, which distinguished from other business types as 
"Electrical Contractors and other Wiring Installation Contractors" that is tracked using a unique census code 238210 under the North American Industry Classification System (NAICS) of data collection and reporting. The three market share metrics are calculated as follows:

- Employees Share is calculated as the ratio between the number of union employees (From NEBF) and the number of productive employees in the electrical construction industry (from the BOC and BLS data). The BOC and BLS data include all employees working in electrical construction firms, including productive (electricians) and the non-productive (administration). As such, a 70\% correction factor is applied to the BOC and BLS data to calculate the productive employees, which was assumed by CLRC based on the U.S. Construction Census data.

- Wage Share is calculated as the ratio between the salaries of union employees (from NEBF) and the salaries of productive employees in the electrical construction industry (from the BOC and BLS data). Similar to the employees share metric, the BOC and BLS data is adjusted using a factor of $64 \%$ based on the latest Construction Census data.

- Employer Share is calculated as the ratio between the number of NECA contractors (as obtained from NECA National) and the number of all electrical construction (as reported under NAICS 238210 in the BOC data).

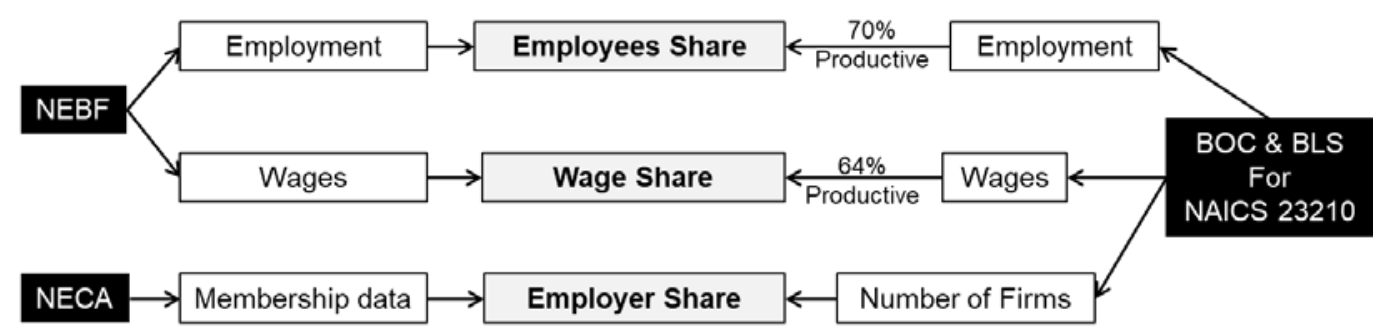

Figure 1. CLRC Inside Construction Trend (ICT) Market Share Metrics Calculation

The CLRC study does not delve deep into the employment and wage data, compared to the NLMCC procedure, as explained next. Due to the limited bandwidth of NECA and CLRC, the ICT report only provides data at the state level, not the county or IBEW locals level. However, NECA kept its commitment to the CLRC ICT studies as an additional benchmark data point beside the NLMCC reports to validate its market share values and trends. NLMCC considers a broader base of electrical workforce by accounting for the electricians who are employed in organizations other than construction firms, like facilities maintenance, manufacturing facilities and energy plants.

\section{NLMCC Annual Inside Market Share Summaries}

The National Labor Management Cooperation Committee (NLMCC) is a trust fund that is sponsored and funded by NECA and IBEW. The NLMCC fund is used for marketing, recruitment and market studies, including its Annual Inside Market Share Surveys. NLMCC market survey adopted the CLRC calculation approach, but with a higher level of details and system adjustments of the government data to reflect the local market conditions. The NLMCC survey has become a source of market share assessment that, to a high degree, is acknowledged by both NECA and IBEW as a common ground for labor agreement bargaining and arbitration. On the other hand, the CLRC report is sponsored by only NECA as a second benchmark. Both metrics do not provide an accurate assessment of the market share level, but rather should be used to evaluate the market share trend. As shown in Figure 2, NLMCC and CLRC data exhibit similar market share trends, but the CLRC values has been historically higher than NLMCC value by about eight percent points. 

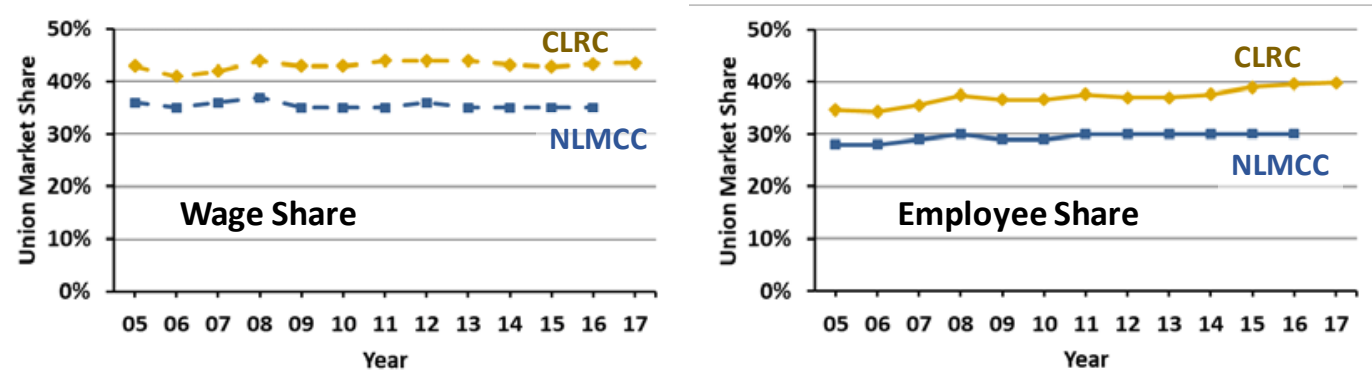

Figure 2. Trend Comparison between NLMCC and CLRC Market Share Metrics

The NLMCC surveys have been performed by a dedicated staff who make micro adjustments of the employment data to provide a more realistic assessment of the union locals. IBEW is interested in making the market share metric reflect the electricians who work in construction-related workplaces other than electrical construction firms, like facility maintenance. Therefore, the NLMCC values are lower than the CLRC values because NLMCC relates the union members to a larger labor market. The NLMCC staff has established a process to aggregate the government employment from the county level to the union local level through the local-county jurisdiction relation. In doing so, the aggregation of the county employment data is adjusted in three ways:

- Similar to CLRC, the government employment data is adjusted from total employment to only productive employment to be able to compare to the NEBF union electrician employment data.

- Unlike the NEBF data, the government employment data is reported to the base county of the electrical construction firm, not the location where the work hours spent. The NLMCC has established a protocol to correct this data discrepancy and identified the specific cases of electrical contractors who cross the borders between different union jurisdictions.

- $\quad$ NLMCC accounts for multi-trade contractors who may report their employment data under different census classifications (electrical, plumbing, ...) from a year to year. The NLMCC has established in-house procedures to adjust the employment values of such contractors.

The NLMCC methodology has two main limitations. First, it does not provide a quantification of the market size in an understandable way, like in building permits or dollar value. Second, the NLMCC method does not measure the size of the major market segments, which is needed to design effective market share recovery strategies that fit the specific needs and conditions of each local union.

\section{COMET Measurement Method}

The COMET metric was developed internally within IBEW to help with its organizing effort. The metric is quick to develop, but is also based on very rough assumptions about the electrical trade proportion within the general population. Based on some undisclosed analysis, IBEW identified an average ratio of electricians to the local population, to be around five electricians for every 1000 general population individuals. Using this electrician ratio and the population within the IBEW local (from the US Census Bureau), the total number of electricians can be estimated within the local. As such, the union market share is calculated by dividing the number of union electricians over the number of all electricians, as shown in Figure 3. 


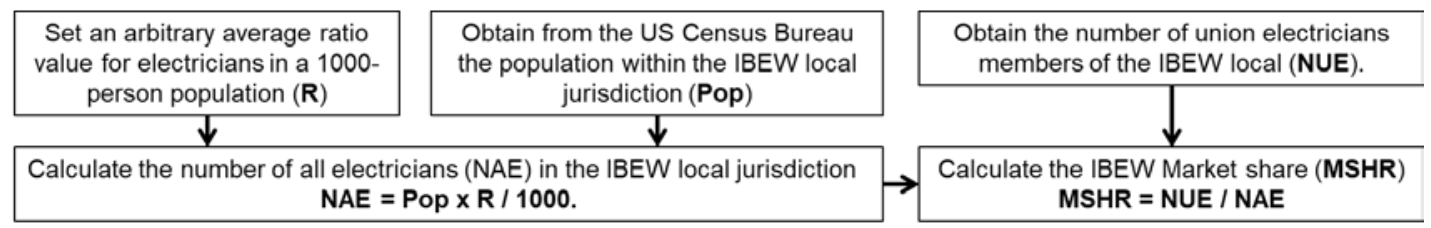

Figure 3. COMET Measurement Methodology

\section{Economic (Sales) Market Size Measurement Method}

Daneshgari et al. (2005) proposed a new economic market size (EMS) measurement methodology to overcome the limitations of other alternative approaches. The economic market size calculation methodology utilizes the economic output of the industry as the common metric to assess the union market share. The researchers found a strong correlation between the generation of electricity, the use of electricity, and the construction industry activity. The analyzed data include: 1) the Construction Put in Place (CPIP) data from the U.S. Bureau of Census (BOC); and 2) the energy generation and energy end use (EEU) from the Energy Information Administration (EIA). The researchers found that the CPIP has had a very strong correlation with both the energy production and EEU. This makes sense, especially for the electrical construction industry that is responsible for building the power infrastructure for energy production and the building electrical system for energy usage.

The developed EMS metric methodology enables the assessment of the local electrical construction market size of specific industry segment in a local area, which can be used by, IBEW local unions, NECA chapters, or individual contractors to assess their market share levels. Figure 4 shows the EMS metric calculation methodology. The total national CPIP value is segregated into the three main market segments (residential, industrial, and commercial) using the EEU data that is broken down by the building types. Then the electrical contracting (EC) portion of this CPIP in each market segment is calculated by a factor that is determined based on the electrical construction data published by the U.S. BOC. By this point, the economic value of the national electrical construction is known. Afterwards, the EC economic value of a market segment in a state is calculated based on the ratio of the state's EEU to the total national EEU value. Next, the EC economic value of a market segment in a county is determined based on the population of the county relative to the total population of the state. Finally, the local union or chapter economic value (market size) of the EC work within a market segment is calculated by adding up its sub values from the counties within the local or chapter jurisdiction. By knowing the value (contract sales) of their own union work, NECA chapters and IBEW local unions can calculate their market share using the calculated market size value. 


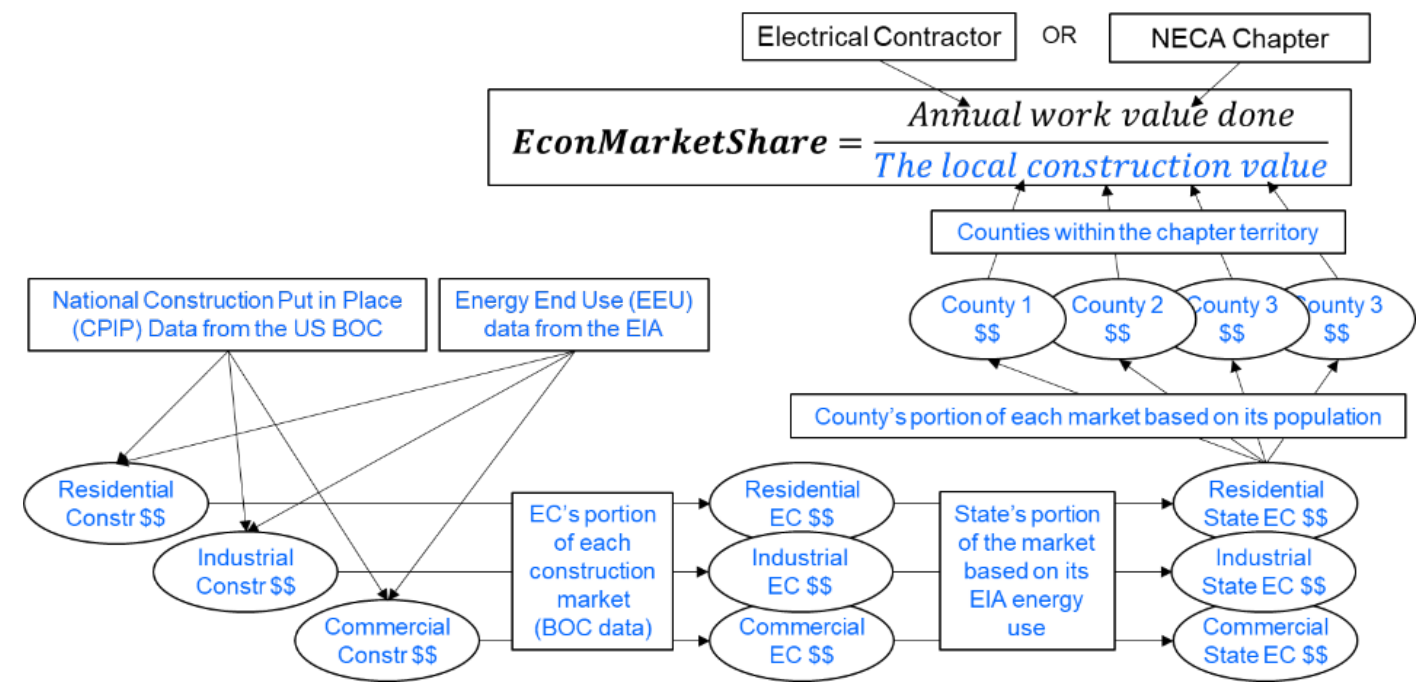

Figure 4. Economic Market Share (EMS) Methodology

Despite the creativity and the hypothesized accuracy of the EMS metric, it was limited to the regional application by NECA chapters and was not utilized for national assessment of the union market share. Based on interviews with NECA and IBEW staff, the national trade organizations have already established a mutual understanding on utilizing the market share values published by NLMCC, and it will be a hard process to change the status quote. NLMCC has become the standard metric for market share assessment and the basis for labor agreement negotiations. However, some NECA chapters have applied the EMS metric and found it to be more reflective of their market share levels. Figure 5 shows the trend comparison between the NLMCC and EMS metrics, where a similar trend was observed for both for the sampled chapters. It is interesting to note that the chapters with the perception of large market share (based on high NLMCC values) are assessed by the economic metric at a lower share. This is the case for the NECA chapters of Chicago, San Francisco, and Illinois.
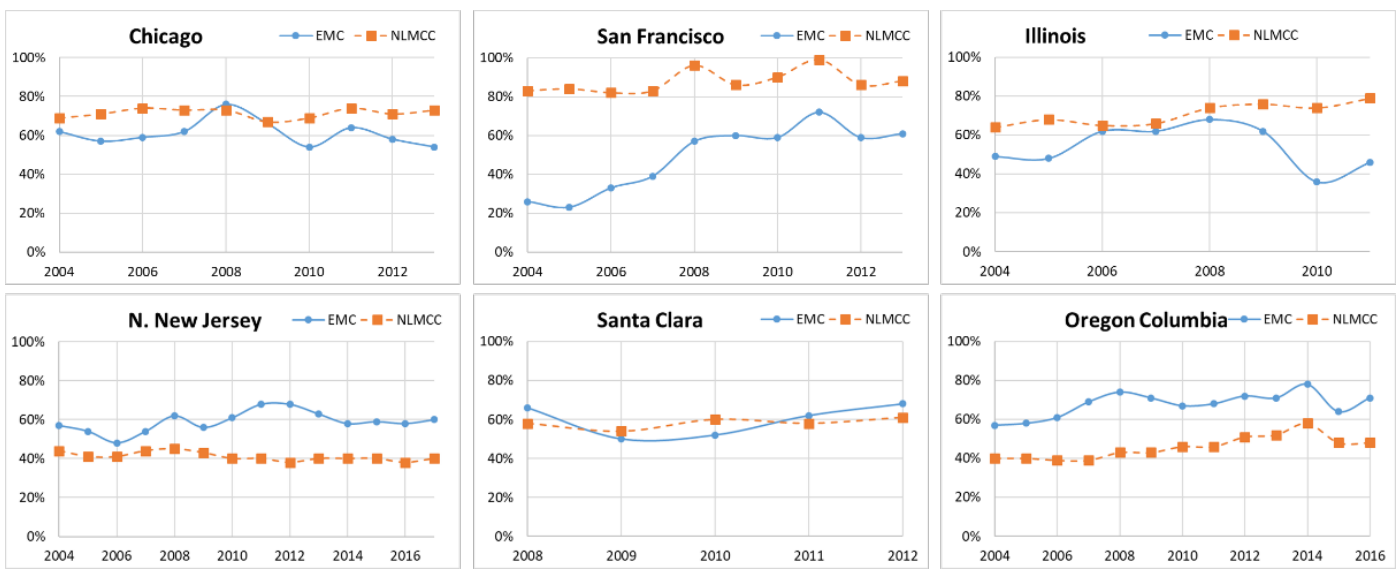

Figure 5. Comparison between EMC and NLMCC Employment Market Share in Six NECA Chapters 


\section{Comparison and Selection of Market Share Metrics}

There is no single market share metric that provides all the qualities needed to have a comprehensive and reliable assessment of the union market share. Table 1 shows the comparison between the four analyzed market share metrics in terms of five main comparison attributes. The best metric would be the one that is: 1) public, or at least, accepted by both the labor and management sides of the union; 2) detailed to the geographic jurisdictions of the local unions; 3) traceable with historical data availability; 4) accurate by being independent or making justified calculation assumptions; 5) detailed by the main segments of the industry; and 4) self-contained in a way that provides market share values without the dependency on additional data collection. Despite its moderate accuracy and lack of market segmentation, NLMC was found to be the most appropriate metric to use for immediate research developments in analyzing union market share dynamics. NLMCC is the only metric that is mutually accepted by both NECA and IBEW, and its data is self-contained and readily available at the union local jurisdiction level. The utilization of the economic metric is currently constrained by its proprietary nature (it is offered as a consulting service through a private firm) and the dependency on the local union or contractors to track the values of their work to calculate the market share value.

Table 1

Comparison between the Analyzed Electrical Construction Union Market Share Metrics

\begin{tabular}{ccccc}
\hline Attribute & CLRC & NLMCC & COMET & EMS \\
\hline Ownership & NECA & NECA \& IBEW & IBEW & Proprietary \\
Geography & State & IBEW Locals & IBEW Locals & Any \\
Historical Data & Available & Available & Not Available & Not Available \\
Accuracy & Moderate & Moderate & Low & High \\
Market Segments & Not detailed & Not detailed & Not detailed & Detailed \\
Self-Containment & Yes & Yes & Yes & No \\
\hline
\end{tabular}

\section{Union Market Share Trend Metric}

The researchers developed an algorithm to analyze the time series data of NLMCC employment market share for each local for the 2004 - 2017 period. The derivative-based algorithm utilizes a mathematical approach (Majumdar and Jayachandran 2018) to determine the shape of a continuous time serios (e.g. convexity, concavity, or linearity) considering the first and second derivatives of the time series. The algorithm helps to automate the process of classifying the market share time series trend, instead of manually analyzing the time series data of all 255 IBEW local unions. The outcome of this algorithm is a classification of the market share trend for each union local unit as either a positive or a negative trend, which entails 4 main classifications:

1. Growth Trend (positive): the local union has gained market share at either a decreasing rate or increasing rate.

2. Rebound Trend (positive): the local union has lost market share, but managed to rebound and gain the lost share.

3. Up-down Trend (negative): the local union has gained some market share to a peak value and then started losing some or all of the gained share.

4. Shrinking Trend (negative): the local union has lost market share at either a decreasing rate or increasing rate. 
A close validation of the market share trend metric was performed by examining a sample of the local union data series. Figure 6 provides the market share trend classifications for four example local unions that experienced a growing, rebound, up-down, and shrinking trends.
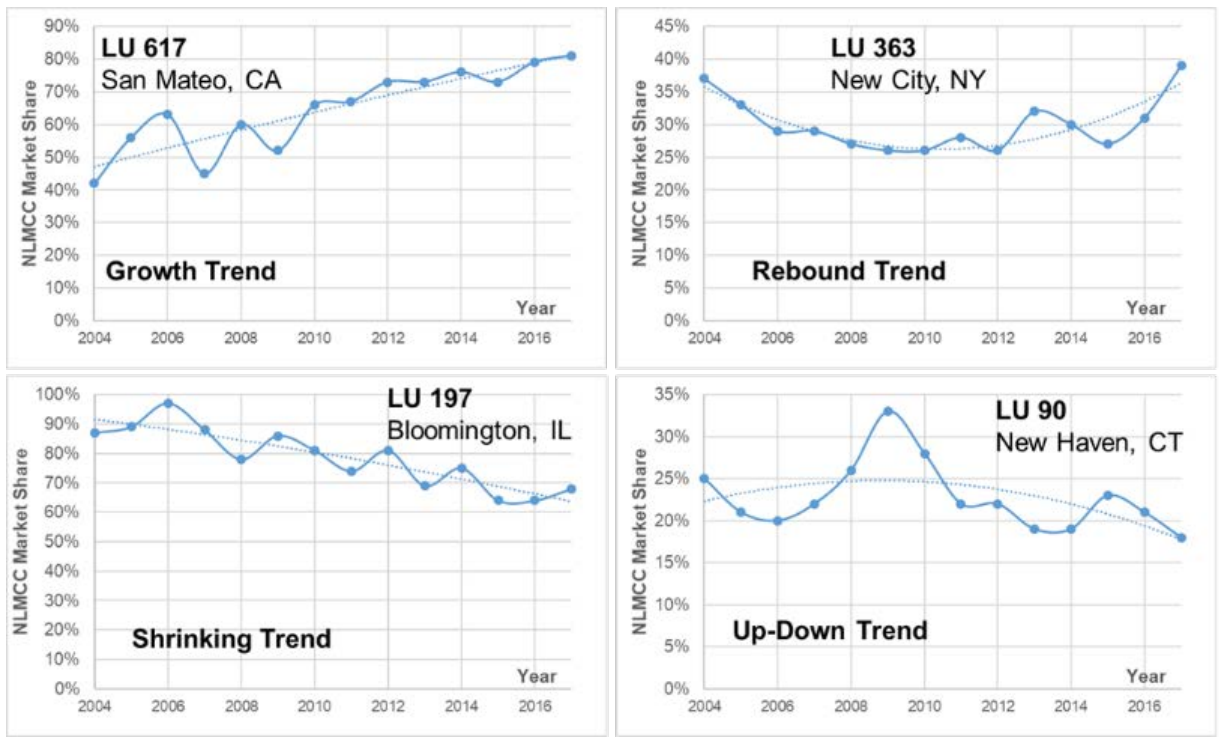

Figure 6. Market Share Trends for Example Local Unions.

\section{Summary}

The construction unionization is not well investigated by the academic community due to the lack of readily available and reliable market data. This paper provides a better understanding of the available union market share metrics, which can be fundamental for future data-driven and quantitative analysis of electrical construction unionization dynamics. Four market share metrics were analyzed by contrasting their ownership, geographical application, historical record availability, accuracy, market segmentation, and self-containment. The NLMCC market share metric was found to be the most available, detailed, and self-contained metric to be used in future research on analyzing the unionization dynamics in the electrical construction industry. To facilitate future research on union construction dynamics, a new trend metric was developed to classify the market share trajectory instead of its estimated value at a specific year.

\section{References}

Allen S. G. (1984). “Unionized Construction Workers are more Productive.” The Quarterly Journal of Economics, 99(2), 251-274, https://doi.org/10.2307/1885525.

Belman D. and Smith A. (2008). Reconstructing Construction Unionism: Beyond Top Down and Bottom Up. Industry Studies 2008 Conference, Alfred P. Sloan Foundation, May 1 - 2, Boston, MA. 
Daneshgari P, Wilson M, and White H. (2005). Market Share: Developing Standard Format to Calculate Market Share. ELECTRI International Report, Link: https://electri.org/product/marketshare-developing-a-standard-format-to-calculate-market-share/

Diekmann J. E. and Peppler S. E. (1984). “Union and Open Shop Labor Cost Differences.” Journal of Construction Engineering and Management, ASCE, 110(1), 87 - 99.

Erlich, M. \& Grabelsky, J. (2005). Standing at a crossroads: The building trades in the twenty-first century [Electronic version]. Retrieved [8/15/2019] from Cornell University, ILR school site: http://digitalcommons.ilr.cornell.edu/articles/281/

Freeman R. B. and Medoff J. L. (1983). “Trade Unions and Productivity: Some New Evidence on an Old Issue.” National Bureau of Labor Statistics, Working paper \#1249, Cambridge, MA.

Kim J. and Philips P. (2012). "Determinants of Quits and Dismissals on a Large-lasting Unionized Industrial Construction Project.” Journal of Construction Engineering and Management, ASCE, (138(5), $661-669$.

Kosla M.T. (2015). “More than Members: Market Revitalization in the Building Trades.” Critical Sociology, Sage, 41(4-5), 735 - 756, DOI: 10.1177/0896920514527847.

Majumdar K. and Jayachandran S. (2018). "A Geometric Analysis of Time Series Leading to Information Encoding and a New Entropy Measure.” Journal of Computational and Applied Mathematics, 328: 469 - 484, 2018.

Maloney W. F. and McFillen J. M. (1994). “Job Characteristics: Union-Nonunion Differences.” Journal of Construction Engineering and Management, ASCE, 121(1), 43 - 54.

U.S. Bureau of Labor Statistics (USBLS) (2019). Union Members Summary. Economic New Release, No. USDL-19-0079, Link: https://www.bls.gov/news.release/union2.nr0.htm

Walters M. and Mishel L. (2003). "How Unions help all Workers.” Online report, Economic Policy Institute, Washington D.C., Link: https://www.epi.org/publication/briefingpapers_bp143/ 